Boston University School of Law

Scholarly Commons at Boston University School of Law

Faculty Scholarship

2011

Germ Shed Management in the United States

Kevin Outterson

Follow this and additional works at: https://scholarship.law.bu.edu/faculty_scholarship

Part of the Health Law and Policy Commons 


\section{BU School of Law}

\section{Germ Shed Management in the United States}

Boston University School of Law Working Paper No. 11-19

(May 11, 2011)

Kevin Outterson

(Boston University School of Law)

Olga Yevtukhova

(Boston University School of Public Health)

This paper can be downloaded without charge at:

http://www.bu.edu/law/faculty/scholarship/workingpapers/2011.html 


\title{
Germ Shed Management in the United States
}

\author{
Kevin Outterson* \\ BU Law \\ Olga Yevtukhova \\ BU School of Public Health
}

Germ Shed Management in the United States, in ANTIBIOTIC POLICIES: CONTROLLING

HOSPITAL-AsSOCIATED INFECTION (Ian M. Gould and Jos van der Meer, eds., Springer, 2011)

(http://ssrn.com/author=340746).

\begin{abstract}
The U.S. Medicare program reimburses only for discrete treatments of individuals with infections, but fails to pay for infection control or antibiotic stewardship more generally. By focusing solely on discrete hospitals and patients, Medicare ignores the larger epidemiological reality - that hospitals, nursing homes and other institutions operate within a germ shed. Under current Medicare rules, institutions that invest in infection control or antibiotic stewardship may actually lose money and benefit rival firms in the market. In effect, current Medicare rules subsidize MRSA pollution. Worse yet, Medicare rules block potentially efficient Coasian contracts to promote private coordination within germ sheds.
\end{abstract}

\section{Germ Sheds}

In the US, Medicare reimburses hospitals as if antibiotic resistance were localized only in the hospital itself. Medicare focuses on hospitals as discrete institutions, as if methicillin-resistant Staphylococcus aureus (MRSA) or other germs respected corporate boundaries on an organizational chart or legal boundaries on a map. US hospitals are paid by the case, but microbes operate in a larger epidemiological environment, a germ shed.

A germ shed is roughly analogous to a watershed: clinical regions that are epidemiologically interdependent and thus share positive and negative infectious disease externalities. For most hospitals, the germ shed will be larger than just the institution, but will also include long-term care facilities that transfer patients to and from the hospital. Other institutions in the germ shed could include

- Corresponding author: mko@bu.edu. I wish to thank Marc Lipsitch of the Harvard School of Public Health for his assistance in the biology of resistance and Aaron Kesselheim, also at the Harvard School of Public Health, for discussions relating to nonpatent coordination mechanisms for antibiotic conservation. This work is supported by research grants from the Robert Wood Johnson Foundation and the David Saul Smith Award from the Boston University School of Law. 
ambulatory surgical centers, rehabilitation facilities, dialysis centers, prisons, schools and the community at large. The existence and scope of a germ shed is empirically established, using epidemiological data. Tools to promote the longterm effectiveness of antibiotics include infection control, vaccination, and antibiotic stewardship and other antibiotic conservation measures (Laxminarayan and Malani, 2007). Our primary insight is that some of these tools should be applied across the germ shed, not just in discrete institutions. This article will focus on MRSA as an example, but the principles may apply to other resistant pathogens.

This chapter explores the problems that US Medicare creates when it fails to modify reimbursement to account for germ sheds. One approach might reimburse regional groups of hospitals for infection control and pay bonuses for reducing infections within the germ shed. Medicare's new value-based purchasing (VBP) initiative is trying to realign some quality incentives, but still focuses just on individual hospitals instead of the larger epidemiological environment. While the Dutch have successfully responded to MRSA on a national basis, the fragmented nature of the US health care market (Elhauge, 2010) makes this type of coordination more difficult.

\section{Germ Shed Issues Within US Hospitals}

\section{A. MRSA pollution from US hospitals}

MRSA pollution occurs when a health care institution does not prevent transmission. MRSA is a significant public health issue in the US (Wenzel, 2007). A recent study by Klevens, et al. found 94,360 invasive MRSA infections in the US in 2005, associated with 18,650 deaths (Klevens et al, 2007). Another study, published nearly simultaneously, found the MRSA infection rate to be higher $(278,203)$ but the death rate lower $(6,000)$ (Klein et al, 2007). While the data remains incomplete (GAO, 2008), the medical community views MRSA as a large and growing public health problem: "Our findings suggest that $S$. aureus and MRSA should be considered a national priority for disease control" (Klein et al, 2007).

As MRSA emerged in the late 1970s, hospitals and other institutional providers turned to vancomycin as an effective treatment. Absent vancomycin, hospitals would have resorted to less effective treatments and implemented additional infection control measures. More patient deaths would undoubtedly have occurred, but a major MRSA crisis in the 1980s might have given the market enough signals to induce more antibiotic R\&D in the following decades. The success of vancomycin dampened the need for other antibiotics in the 1980s and 1990s, much as methicillin dominated in the 1960s and 1970s. Vancomycin's success in the 1980s and 1990s contributed to the antibiotic incentive problem 
that many identify today (Talbot et al, 2006; Norrby, et al, 2005; Wenzel, 2004; Outterson, 2010). ${ }^{1}$

Vancomycin's effectiveness in the last few decades permitted higher levels of MRSA pollution, both within the hospital as well as the larger germ shed. Vancomycin temporarily raised the optimal level of MRSA pollution and reduced the cost-effectiveness of both conservation and rival product R\&D.

\section{B. Reimbursement under US Medicare}

\section{Hospital internal incentives under US Medicare}

Hospitals can adopt control measures to reduce the internal and external levels of MRSA pollution. In economics textbooks, most of the cost of pollution falls on property owners downwind; a classic externality. MRSA pollution creates infectious disease externalities when infected patients are discharged or transferred, but a significant portion of the cost also falls on the hospital itself or its patients.

Let us therefore initially consider the internal costs. Ideally, infection control and antimicrobial stewardship would be financially rewarding for the hospital. Unfortunately, Medicare does not have a billing code for infection control or antimicrobial stewardship. These activities are cost centers for a US hospital, not direct sources of revenue. This is a first-order error if our goal is to promote longterm effectiveness of antibiotics. But perhaps the hospital can make a business case for antibiotic conservation, investing to reduce costs. An authoritative review of the medical literature concluded that:

"Effective antimicrobial stewardship programs can be financially self-supporting and improve patient care. Comprehensive programs have consistently demonstrated a decrease in antimicrobial use (22\%-36\%), with annual savings of $\$ 200,000-$ $\$ 900,000$ in both larger academic hospitals and smaller community hospitals" (Dellit et al, 2007).

This statement begs a question. If indeed the internal business case for antimicrobial conservation in hospitals is clear, then we should expect rational hospital executives to implement such programs. But the cost savings described above are illusory because they are based on "billed" charges (which are almost never actually billed) rather than actual Medicare reimbursement. The US reimbursement system is complex, with diverse financial incentives. The following paragraphs will examine the interaction between the Medicare

\footnotetext{
${ }^{1}$ If resistance stimulates innovation, then a corollary may be that a lack of resistance dampens innovation, but it dampens exactly the sort of innovation that we don't need.
} 
reimbursement system and the direct internal savings in antimicrobial stewardship programs.

US hospitals contract with many health plan payors, both private and public. The most important payor is Medicare. Medicare's reimbursement system is important for two reasons. First, it is a very large program, constituting the largest single revenue source in most US hospitals (GAO, 2008). Second, some private health plans have voluntarily adopted Medicare's reimbursement methodology, which magnifies its importance through a spillover effect (Dove, 1994; Nichols et al, 2006; Henderson and May, 1983).

Until the early 1980s, Medicare reimbursed hospitals on a cost basis. Hospitals reported their allowable costs to Medicare, and those costs were paid, with an implicit mark-up for operating margin. ${ }^{2}$ Over time, many policy experts recognized the inflationary effect of cost-based reimbursement. Hospitals lacked a financial incentive to cut costs. Rampant cost expansion followed (Scanlon, 2006). For example, if a hospital had implemented an antimicrobial stewardship program during cost-based reimbursement, the "savings" would be illusory, since the reduced costs would also reduce revenues. ${ }^{3}$ Worse yet, the hospital would lose the implicit mark-up on the foregone costs. This reimbursement system actually punished cost-saving measures such as antimicrobial conservation during the first decades of the Medicare program. ${ }^{4}$

For a time, the US Government fought back against higher hospital fees with increasingly complex rules for allowable charges. ${ }^{5}$ These rules frequently resulted in protracted litigation over cost-based reimbursement. Rule articulation eventually proved both unwieldy and ineffective (Frankford, 1993). In fiscal year 1983, Congress switched most US hospitals from cost-based reimbursement to prospective payment. The program is now called the inpatient prospective payment system (IPPS). ${ }^{6}$ Under this system, the Centers for Medicare and Medicaid Services (CMS) organized hospital diagnoses and procedures into a list of diagnostic-related groups (DRGs), and announced a fixed price in advance for each DRG. The prices are based on a complex formula, which changes from year to year, and varies somewhat by geographical region and other factors such as wage costs.

\footnotetext{
242 C.F.R. $\S 405.402(a)$ (1982).

${ }^{3}$ If the cost-saving program generated spillover savings for patients reimbursed under other methodologies, then it is possible that the hospital would have improved its bottom line. To the extent that other payors followed Medicare's reimbursement model, these savings would disappear as well.

${ }^{4}$ This assumes that conservation programs were actually cost effective. If they raise net costs, then all of the incentives discussed in this section are inverted.

${ }^{5}$ See, e.g., Social Security Amendments of 1972, Pub. L. No. 92-603, 86 Stat. 1329 (the "section 223 limits").

${ }^{6}$ Sec. $1886(d)$ of the Social Security Act.
} 
Economic incentives are quite different under IPPS. Hospitals now benefit if they trim costs, since their payment is no longer tied to actual expenditures. This new reimbursement system has dramatically reshaped the US healthcare sector (Scanlon, 2006). The Medicare reimbursement system now picks winners and losers on a macro level, favoring some procedures, services and patients over others. Profit variations occur both within and across DRGs. Variation within a DRG creates opportunities for favorable or unfavorable selection of patients. Admitting a sicker than average patient within a particular DRG may cause the hospital to lose money; admitting healthier than average patients has the opposite effect.

CMS has implemented methods that discourage adverse selection by providers. One such technique has been to divide single DRGs into narrower categories, which limits a hospital's ability to avoid high-cost patients. Another is to complicate DRGs by adding features such as co-morbidity modifiers, essentially splitting many DRG into multiple subgroups. ${ }^{7}$ In general, the presence of MRSA in a patient can result in higher reimbursement under the DRG. The economic incentives favor treatment rather than prevention. Put another way, a highly successful antibiotic conservation program in a hospital will not generate additional Medicare revenue and will probably reduce revenues when less intensive co-morbidity modifiers are billed.

Medicare IPPS has other systemic effects on US hospitals. Variations across DRGs make some procedures and services more profitable than others. For example, the site of elective surgeries shifted dramatically since 1984, as the Medicare reimbursement system favored ambulatory surgical centers (ASCs) over hospital inpatient surgeries through a special payment rule. Many profitable surgeries migrated from typical inpatient settings to ASCs and specialty hospitals.

Finally, the boundaries between DRGs have encouraged unbundling services into different facilities in order to earn a new DRG. For example, early dismissal from a hospital might earn the full DRG, even if the patient was transferred to a post acute facility owned by the hospital. Hospitals responded to these financial incentives by discharging patients much more quickly, reducing US average length of stay below the Organization for Economic Cooperation and Development (OECD) median (Pearson, 2009). Hospitals achieved this reduction in part by substituting post-acute care for inpatient services (Ashby et al, 2000). The federal government is concerned about these potential distortions and is acting to reduce them (MedPac, 2007a), but new initiatives frequently lead

\footnotetext{
${ }^{7}$ Medicare is now transitioning to the MS-DRG system with 258 sets of DRGs, each split into two or three subgroups depending upon the presence or absence of a "complication or comorbidity" (CC) or major complication or comorbidity" (MCC). The total number of DRGs now exceeds 700.
} 
to new unintended consequences (Werner et al, 2008). Each new adjustment adds layers of complexity to the Medicare reimbursement system. Some critics now resort to satire and mock Medicare's devilish details (Hyman, 2006).

The IPPS is still biased in favor of diagnosis and treatment rather than conservation and prevention. Medicare has not created a reimbursable DRG code for hospital infection control efforts, antimicrobial stewardship programs, or special isolation procedures for MRSA. Medicare wants something that it isn't willing to pay for directly.

\section{Hospital germ shed externalities under US Medicare}

Hospital infection control efforts generate many positive externalities when infections and further resistance are prevented. Beneficiaries from avoided infection include the treated patient, other patients, hospital staff, other providers such as long-term care facilities, health insurance payors such as Medicare and commercial companies, and the community.

Epidemiologists and public health professionals attempt to maximize these positive externalities by reducing the spread of infectious disease. These benefits can accrue over time: conservation and infection control today may also improve the health of future patients, both through reduced transmission and the sustained availability of effective antimicrobial agents in future years (Laxminarayan and Malani, 2007).

Competitive problems emerge when these positive externalities benefit other institutions in the market. For example, in a two-hospital town, if one hospital achieves excellent MRSA control, those efforts should reduce the number of MRSA colonized patients admitted to both hospitals. The first-mover hospital incurs costs for infection control and a portion of the resulting benefits accrue to its direct competitor in the market. Likewise, infection control in a long-term care facility benefits the hospitals to which its patients are transferred, and vice versa. If these institutions are not under common ownership, infection control benefits other institutions, perhaps competitors. Antibiotic stewardship programs also generate positive externalities to society, above and beyond the direct savings to institutions. The economic problem is how to pay for these activities that benefit others. Germ shed management is therefore a collective action problem.

Medicare reimbursement currently treats these positive externalities and collective action problems with indifference, at best. ${ }^{8}$ Consider IPPS

\footnotetext{
${ }^{8}$ In ordinary medical care, positive externalities include the continued contributions by the patient to society. IPPS doesn't reimburse for these social gains, although some prescription drug pricing in Australia and Europe takes this approach. Treatment of infectious diseases always generates the additional positive externality of epidemiology. While the calculation of the social benefits from health might seem remote and
} 
reimbursement and infection control. Infection control requires meticulous attention to detail, including very thorough cleaning, barrier controls, and isolation. These activities are not free. Under cost-based reimbursement, hospitals may have earned a positive margin on infection control. Under IPPS, infection control is part of the cost structure and never generates revenues. These are odd signals in our reimbursement system.

At first glance, IPPS favors antibiotic stewardship programs. Reducing prescription costs will improve the hospital's operating margin. But this equilibrium is disturbed if the DRG is modified for infections. When patients acquire a nosocomial infection, the hospital may qualify for additional reimbursement for the complication or co-morbidity. Hospitals can earn additional revenues from nosocomial infections. ${ }^{9}$ If the infection results in a readmission, even more revenue may accrue. The amounts involved are significant. For the average hospital-acquired infection, hospital costs were an additional $\$ 8,832$ Murphy and Whiting, 2007). Infection with resistant bacteria can double hospital costs (French, 2005).

Hospitals do not deliberately cause infections in order to increase revenue, but one unintended effect of the Medicare reimbursement system is to send mixed financial signals to hospitals about nosocomial infections. As Leah Binder of the Leapfrog Group testified to Congress, "We must assume that money is concentrated at hospitals with the worst record for hospital acquired infections. This perverse payment system impedes the implementation of critical quality processes." (Binder, 2008). Certainly the hospital is not rewarded for creating these positive infection and resistance prevention externalities; it is possible that they are actually punished financially for helping others.

\section{B. Legal barriers to private ordering}

In an ideal Coasian world, hospitals could contract with the other institutions in their germ shed, allocating the positive and negative MRSA externalities through private ordering. Medicare explicitly makes many of these activities felonies through the fraud and abuse laws. In the US, it is illegal for a provider such as a hospital to make or receive a referral for many designated health services, if the two have a financial relationship. It would be illegal for a hospital to contract with an independent long-term care facility to coordinate infection control and antibiotic conservation generally if that contract anticipated any financial flow in

speculative, perhaps infectious disease control can make a stronger case for winning a slice of the epidemiological externality as reimbursement.

${ }^{9}$ Whether the additional revenues offset the additional expenses is another matter. It is also possible that a MRSA-free hospital would be more profitable, even without secondary diagnosis payments (GAO, 2008) ("Hospitals may also incur some of the cost because they are not fully reimbursed for the cost of the extra care attributable to HAIs."). 
either direction. In other words, Medicare prohibits private ordering to capture germ shed externalities.

US competition law also would look askance on contracts between horizontal competitors such as the hospitals in a germ shed. If the contract did not engage in naked price fixing or market segmentation it might not be per se illegal, but would still suffer potential review and liability for violation of US antitrust laws.

Congress must modify these laws if germ shed management is to occur through private contract. Otherwise, the coordinating mechanism must be Medicare. The following section explores that option, in all its complexity.

\section{Creating markets for hospital quality in US through Medicare}

Medicare has not historically modified reimbursement for quality of care: both high quality and low quality care have been paid under the same DRG. Medicare has historically relied on professionalism, accreditation and the tort system to support minimum quality standards (GAO, 2008). Medicare is currently experimenting with quality-related modifications to its reimbursement system. ${ }^{10}$ Some of these modifications are important for infectious disease. Supporters characterize these changes as pay-for-performance (P4P) or VBP, creating a market for quality within Medicare. After describing the initiatives in some detail, we will evaluate their impact on MRSA germ shed externalities.

\section{A. Paying for reporting of information}

Assessing quality in Medicare depends upon timely and accurate data. In the Medicare Modernization Act of 2003, Congress ostensibly offered a carrot to hospitals, offering additional Medicare reimbursement (through the Annual Payment Update or APU) in exchange for reporting some hospital quality measures. ${ }^{11}$ In reality, the offer was less carrot and more stick. The latest version reduces the APU by two percentage points for any hospital that does not "voluntarily" participate. ${ }^{12}$ For larger hospitals, this reduction would be millions of dollars. The great majority of US hospitals participate, about $93 \%$ of the eligible hospitals (GAO, 2008).

${ }^{10}$ See, e.g., Changes to the Hospital Inpatient Prospective Payment Systems and Fiscal Year 2008 Rates, 72 Fed. Reg. 47130, at 47200 (Aug. 22, 2007) (final rule); and FY 2009 Proposed Rule, 73 Fed. Reg. 23528, 23530 (April 30, 2008).

${ }^{11}$ Pub. L. 108-173, 117 Stat. 2066 (Dec. 8, 2003). The law was amended in Pub. L. 109171, Section 5001(a) (2005), amending Section 1886(d)(3)(B) of the Social Security Act (42 U.S.C. section $1395 \mathrm{ww}(\mathrm{d})(4)$ ). The first 10 hospital quality measures were proposed for reporting as of November 1, 2003.

${ }^{12} 42$ U.S.C. sec. 1395ww(b)(3)(B)(viii)(I). 
As with all things Medicare, the scope and complexity of reporting will increase over time. Originally, Medicare requested reporting of 10 hospital quality indicators. ${ }^{13}$ Subsequently, Medicare has asked for comments on 26 additional "pay for reporting" datasets (MedPAC, 2007a). The latest proposed rule adds 43 more for FY 2009. ${ }^{14}$ Several of these datasets relate to infectious diseases, including a surgical infection dataset (MedPAC, 2007a). This measure may lead to payment restrictions based on preventable readmissions (MedPAC, 2007c). Some states simply require hospitals to publicly report certain hospitalassociated infection information (Pennsylvania, 2008). These data collection efforts are disjointed, but will form the basis for future policy (GAO, 2008).

Reporting hospital-associated infections is a good first step towards identifying and quantifying MRSA pollution, but thus far no public database is tracking discharge of patients carrying MRSA or present on admission (POA) statistics from particular facilities. These specialized reports are the sort of information needed in order to better quantify germ shed pollution externalities.

\section{B. Process measures: mandating best practices}

The Medicare pay-for-reporting program includes three measures on infectious diseases. All three track processes rather than outcomes: (1) providing prophylactic antibiotics within one hour of surgery; (2) selecting appropriate antibiotics to prevent surgical infections; and (3) stopping prophylactic antibiotics within 24 hours after surgery. These statistics are available to the public on Medicare's website, as part of the program to provide better health care information to consumers. Many of the relevant accreditation standards from the Joint Commission are also process standards.

One weakness in the US health sector is measuring and rewarding inputs or processes rather than outcomes. Expensive inputs don't necessarily yield high quality care. The United States outspends the OECD and deploys the latest technology, but with modest comparative results.

Similar questions plague process-based reimbursement. Procedures may result in good outcomes, but sometimes they do not. A parallel controversy in drug development would be evaluating efficacy on intermediate clinical endpoints (such as lowering cholesterol) instead of actual clinical outcomes (reduced mortality from heart disease). Each of the three processes selected for the Medicare program appears to be reasonable and helpful, but their actual impact on patient health and antimicrobial resistance is not yet established.

Focusing on processes rather than outcomes runs the risk of teaching to the test. Hospitals may over invest in the listed processes, to the relative neglect of other

${ }^{13}$ See FY 2009 Proposed Rule, 73 Fed. Reg. 23528, at 23643 (April 30, 2008).

${ }^{14}$ FY 2009 Proposed Rule, 73 Fed. Reg. 23528, at __ (April 30, 2008). 
actions that might yield better patient outcomes. For example, evidence suggests that hospitals achieve higher compliance with processes when measured (MedPAC, 2003). Whether this is the best medical care available with the given resources is left unanswered at present. This question will turn on how carefully the processes were chosen, and how they are adapted to local conditions and constraints. In essence, some standards of medical care have been federalized when Medicare adopts a medical process by administrative procedure. This step represents a major change from the original promise that Medicare would not interfere in the practice of medicine. Nor is it likely to remain cabined in a niche of the Medicare program. The Government Accountability Office recently recommended that CMS adopt some of these standards into Medicare's Conditions of Participation (GAO, 2008).

\section{Outcomes measures: punishing preventable errors}

The Deficit Reduction Act of 2005 introduced outcome measures related to reasonably preventable errors. ${ }^{15}$ Congress instructed Medicare to identify reasonably preventable errors relating to at least two DRG codes. Medicare responded with enthusiasm, suggesting 13 errors for further study. ${ }^{16}$ After a process involving the Centers for Disease Control and Prevention, health care industry lobbyists, Medicare Payment Advisory Committee (MedPAC), and others, Medicare identified six hospital-based errors in its FY 2008 Final Rule. ${ }^{17}$ These six are sorted into two categories: "serious preventable events" and "reasonably preventable events." In the FY 2009 Proposed Rule, Medicare collectively refers to these errors as "hospital-acquired conditions" or "HACs." 18 A better term would be "hospital-associated conditions," as Medicare should not assume causation.

Serious preventable events are also called "never events" - implying that they should never happen in a hospital. CMS identified three in the FY 2008 Final Rule: objects left in the body during surgery; air embolisms; and blood incompatibility. ${ }^{19}$ In Medicare's view, these three errors are so fundamental that they should never occur. All three are in fact exceedingly rare. In FY 2006, CMS found just 764 Medicare beneficiaries with objects left during surgery, 45 who suffered from air embolisms, and only 33 with mismatched blood products. ${ }^{20}$

${ }^{15}$ Pub. L. 109-171, Section 5001(c) (2005), amending Section 1886(d)(4) of the Social Security Act (42 U.S.C. section 1395ww(d)(4)).

${ }^{16}$ Proposed Changes to the Hospital Inpatient Prospective Payment Systems and Fiscal Year 2008 Rates, 72 Fed. Reg. 24680 (May 3, 2007) (proposed rule).

${ }^{17}$ Proposed Changes to the Hospital Inpatient Prospective Payment Systems and Fiscal Year 2008 Rates, 72 Fed. Reg. 24680 (May 3, 2007) (proposed rule).

${ }^{18}$ FY 2009 Proposed Rule, 73 Fed. Reg. 23528, at 23529 (April 30, 2008).

${ }^{19}$ FY 2008 Final Rule, at 47201-02.

${ }^{20}$ FY 2008 Final Rule, at 47206-07. 
In the Medicare billing process, HACs may be coded as secondary diagnoses, and prior to this new rule, a hospital could receive additional IPPS revenues for the additional complication. ${ }^{21}$ Whether an additional payment is made depends, in part, on whether the pairing of the original condition plus the secondary diagnosis qualifies for higher reimbursement as a MS-CC DRG. For example, the diagnostic code for leaving a foreign object in the body after surgery is ICD-9CM code 998.4. That code qualifies as a "complication or comorbidity" (CC) that modifies the primary DRG for higher payment. Some serious preventable events are not listed as a CC, so Medicare has never paid additional reimbursement for those mistakes. When the code is not a CC, Medicare is already refusing to pay for the mistake, and there is no need to further adjust reimbursement.

The second category includes less fundamental errors that Medicare believes are "reasonably preventable." In the FY 2008 Final Rule, three were selected: pressure ulcers (bed sores); hospital-associated infections (catheter-associated urinary tract infections); and Staphylococcus aureus bloodstream infection/septicemia. Beginning in October 1, 2008, Medicare will not allow these three secondary diagnoses alone to qualify the DRG for a higher reimbursement level (MedPAC, 2007a). The ICD-9-CM codes associated with these "reasonably preventable" errors will no longer qualify as a CC.

These changes may not make much financial difference. The Congressional Budget Office scored the statutory authority as having a modest budget impact over a decade (CBO, 2006), ${ }^{22}$ and MedPAC expects "the penalties to be applied in relatively few cases." (MedPAC, 2007a). One reason is that if multiple CCs are present, Medicare only pays the upgrade once. The FY 2008 Final Rule blocks the 6 errors as CCs, but many patients have more than one secondary diagnosis. If at least one of them remains a $\mathrm{CC}$, then reimbursement will remain unchanged at the higher level.

MedPAC suggests that Medicare apply a stricter rule to "never events," denying any $\mathrm{CC}$ upgrade, despite the presence of other CCs. MedPAC believes that Medicare has authority to create this rule administratively, without further Congressional action (MedPAC, 2007a). The President apparently agrees, since his FY 2009 Budget proposed this stricter rule without seeking Congressional authorization. ${ }^{23}$ Private payors are also adopting similar rules restricting reimbursement for "never events." (Binder, 2008). This is another example of the spillover effect of Medicare reimbursement rules.

\footnotetext{
${ }^{21}$ Technically, the hospital is being paid for the additional costs associated with treating someone after these events, such as re-opening the body to retrieve the lost object. It is possible that the hospital may have lost money on the secondary diagnosis, but P4P proponents argue that any payment reinforces poor quality.

22 Recently, CMS has estimated the budget impact at \$50 million per year. FY 2008 Proposed Rule, at 23915.

${ }^{23}$ See FY 2009 Proposed Rule, at 23548.
} 
Fiscal impact will also be reduced as hospitals improve quality. More cynically, hospitals will also learn to adjust billing and coding practices to minimize reporting these errors as solitary secondary diagnoses. In any event, these quality incentives are the leading wedge in a much larger value-based purchasing initiative in Medicare. If the history of Medicare is any guide, these rules will significantly expand in scope and complexity over time. But these provisions are unlikely to lead to much litigation, because Congress blocked judicial review of the selection and revision of these codes. ${ }^{24}$ Absent judicial review, we rely entirely on Medicare's administrative process for selecting particular processes and outcomes as "best practices" through the reimbursement system. The next section discusses potential weaknesses in allowing Medicare to be the final arbiter of evidence-based medicine.

\section{Federalizing the standard of care?}

Congress limited the Medicare penalties to "conditions that could reasonably have been prevented through the application of evidence-based guidelines." ${ }^{25}$ If this is a patient-based standard, then Medicare would need to evaluate the facts and circumstances of every particular care episode and judge whether the HAC was both caused by the hospital and reasonably preventable through the use of evidence-based guidelines. If this were the case, then Medicare would be federalizing malpractice law for HACs. In the US, malpractice law has historically been controlled by the states.

But Medicare approaches these evidence-based guidelines from a populationhealth perspective. While each element of the reimbursement process relates to a particular patient, the decision on whether the HAC is reimbursable is made at an abstract level, using population-based averages. Several questions are raised by this approach.

\section{Evidence-based guidelines}

First, Medicare proclaims certain evidence-based guidelines as the standard of care, but they probably don't really mean it. For example, Medicare relies on CDC guidelines and the recommendations of the Healthcare Infection Control Practices Advisory Committee (HICPAC). These are proclaimed as the standard of care in Medicare's value-based purchasing initiative:

"CDC produces evidence-based guidelines that serve as the standard of care in U.S. hospitals and guide the clinical practices of

\footnotetext{
${ }^{24} 42$ U.S.C. sec. $1395 \mathrm{ww}(\mathrm{d})(7(\mathrm{~B})$, as amended by Section 5001(c) of the Deficit Reduction Act of 2005.

${ }^{25}$ Pub. L. 109-171, Section 5001(c) (2005), amending Section 1886(d)(4) of the Social Security Act (42 U.S.C. section 1395ww(d)(4)).
} 
physicians, nurses and other providers... Overall, these guidelines represent over a thousand evidence-based recommendations which, while large in number, address the vast complexity of modern medical care. All of the recommendations are prioritized according to the quality of evidence available to support them." (Wright, 2008).

I doubt that Medicare intends to federalize malpractice by proclaiming a national standard of care. Medicare consulted these guidelines when it created the HAC list for reimbursement cuts. The intended meaning may be something closer to the following:

"These evidence-based guidelines should be consulted by physicians and institutions when making their treatment decisions as professionals, in consultation with the patient after informed consent. In some cases, evidence-based standards may disagree, or may not reach a clear conclusion. In others, best medical treatment will require departure from evidence-based standards. Medical care cannot guarantee positive outcomes, even when the standard of care was followed. Nevertheless, Medicare will deny reimbursement for certain HACs, even if evidence-based guidelines were followed precisely." 26

Medicare discusses the guidelines because Congress required each identified HAC to have "evidence-based guidelines" demonstrating that the HAC was "reasonably preventable." Nothing in Section 5001 of the Deficit Reduction Act of 2005 requires the actual adoption of the referenced standards into medical practice.

\section{Causation}

A related question centers on causation. The FY 2008 Final Rule consistently uses the phrase "hospital-acquired." ${ }^{27}$ The medical literature generally uses a more modest and less determinate phrase, "hospital-associated," "health careassociated," or "community-associated" infections (Dellit et al, 2007). The differences between association and causation are significant, as any statistician will attest.

And yet the FY 2008 Final Rule denies reimbursement as if all HACs were "caused" by a preventable hospital error. Medicare denies reimbursement for HACs based on what is essentially strict liability. The medical community has raised this issue, but has done so ineffectively to date. Some commentators on

${ }^{26}$ Author's text. There is no exception in the MAC process for having followed the referenced standard of care.

${ }^{27}$ FY 2008 Final Rule, at 47201. 
the FY 2008 Final Rule "expressed concern that not all hospital-acquired infections are preventable and noted that sicker and more complex patients are at greater risk for hospital-acquired infections and complications." ${ }^{28}$ In the preamble to the FY 2008 Final Rule, Medicare appeared to skirt the issue:

"Thus, we are only selecting those conditions where, if hospital personnel are engaging in good medical practice, the additional costs of the hospital-acquired condition will, in most cases, be avoided and the risk of selectively avoiding patients at high risk of complications will be minimized." 29

Following the statutory mandate, CMS reviewed many evidence-based guidelines and found sufficient evidence for several conditions to be classified as "could reasonably have been prevented through the application of evidencebased guidelines." ${ }^{30}$ Two HACs related to infections are:

"Surgical site infections. The groups and organizations stated that there were evidence-based measures to prevent the occurrence of these infections..." 31

"Catheter-Associated Urinary Tract Infections... There are widely recognized guidelines for the prevention of catheter-associated urinary tract infections. Guidelines can be found at the following Web site: http://www.cdc.ncidod/dhqp/gl--catheter--assoc.html." ${ }^{32}$

Others were not chosen in the FY 2008 Final Rule, due to a lack on consensus on the causal evidence on preventability:

"Ventilator-associated pneumonias. The groups and organizations indicated that these conditions are currently measured and reported through SCIP. However, other organizations counseled against selecting these conditions because they believed it was difficult to obtain good definitions and that it was not always clear which ones are hospital acquired."33

\footnotetext{
${ }^{28}$ FY 2008 Final Rule, at 47200.

${ }^{29}$ FY 2008 Final Rule, at 47201. Note also the concern about adverse selection by hospitals and the ease with which CMS dismisses it.

${ }^{30}$ Pub. L. 109-171, Section 5001(c) (2005), amending Section 1886(d)(4) of the Social Security Act (42 U.S.C. section 1395ww(d)(4)).

${ }^{31}$ FY 2008 Final Rule, at 47201.

${ }^{32}$ FY 2008 Final Rule, at 47203.

${ }^{33}$ FY 2008 Final Rule, at 47201.
} 
"Pneumonia... Some commentators mentioned that while prevention guidelines exist for pneumonia, it is not clear how effective these guidelines may be in preventing pneumonia." 34

"Clostridium difficile-associated disease (CDAD)... While prevalence of this condition is emerging as a public health problem, there is not currently a strategy for reasonably preventing these infections." 35

While the language is imprecise, the essence of Medicare's approach is as follows: For some diseases, evidence-based guidelines aren't yet proven to make a significant impact on patient outcomes. For others, the statistical evidence is better, and CMS will utilize those guidelines to select specific conditions to add to the HAC list. The act of denying reimbursement in any particular case is not an evaluation of whether any deviation from the standard of care occurred. The HAC may not have been reasonably avoidable, even with the best medical care. Nevertheless, Medicare will deny reimbursement. ${ }^{36}$

Medicare's approach to causation is revealed in the concept of "present on admission" or POA. Medicare will soon require hospitals to report whether CCs and MCCs were present on admission. This reporting originally did not affect reimbursement, but now POA is used to define when a CC or MCC is "hospitalacquired." Medicare will treat all CCs and MCCs as hospital-acquired unless they were reported as present on admission.

Several aspects of this rule seem unfair in the infectious disease context. The FY 2008 Final Rule proposed two infectious disease HACs: surgical site infections and catheter-associated urinary tract infections. Hospitals do not routinely screen for infections on admission, but they will either need to screen for urinary tract infections on admission or face reimbursement cuts if a catheterassociated urinary tract infection occurs. It is unclear what type of diagnostic screening will be helpful to establish POA for surgical site infections. It is also unclear when the test itself must be done. Perhaps hospitals can take samples on admission, but only complete the test if needed for billing purposes. That would save the hospital money on diagnostic testing, but would seem contrary to the purpose of testing.

The possible addition of MRSA and CDAD as HACs might require testing of every patient entering the hospital. This might be appropriate as an infection control measure, especially if it is adopted across an entire germ shed, but here it

${ }^{34}$ FY 2008 Final Rule, at 47201.

${ }^{35}$ FY 2008 Final Rule, at 47201 . Medicare is now overcoming its initial uncertainty regarding CDAD. The FY 2009 Proposed Rule included CDAD on the HAC candidate list. FY 2009 Proposed Rule, at 23558.

${ }^{36}$ The HAC rule does not include any exception for non-negligent care. 
might be implemented as a reimbursement rule, untethered to best medical practice.

\section{Creating new diagnostic codes for MRSA infections}

A third question concerns creating diagnostic codes to facilitate adding new conditions to the HAC list. Some HACs were not selected in part due to the absence of an appropriate ICD-9-CM code. In the MedPAC public meeting discussing the proposal, MedPAC Research Director Jack Ashby stated:

"Many were surprised that CMS did not include MRSA infections in this program, given the attention that these drug-resistant infections have received, but MRSA is not a CC or major CC so its presence alone would not result in additional payment and that pretty much disqualified it from the criteria of this program. But in addition to that, there is some question as to whether this infection can always be detected at admission." (MedPAC, 2007b).

Ventilator Associated Pneumonia (VAP) was also excluded due, in part, to the absence of an appropriate ICD-9-CM code.

But this problem is easily corrected. Medicare controls the creation and modification of ICD-9-CM codes. The ICD-9-CM Coordination and Maintenance Committee has been working on a new code for VAP since at least 2004 (ICD, 2004). Medicare discussed the need for a new code for VAP at the September 29, 2006 meeting of the ICD-9-CM Coordination and Maintenance Committee. ${ }^{37}$ The new code was adopted a year later (ICD, 2007). With the new code in place, Medicare has now added VAP to the HAC candidate list in the FY 2009 Proposed Rule, along with five other infectious conditions. ${ }^{38}$ Many of these additions to the HAC candidate list deserve comment, but we will limit our attention to MRSA.

\section{E. MRSA as a "reasonably preventable condition"}

In the FY 2009 Proposed Rule, Medicare announced that MRSA (and CDAD) were candidates for inclusion in the HAC list. ${ }^{39} \mathrm{CMS}$ is proclaiming that both conditions are "reasonably preventable through the application of evidencebased guidelines." ${ }^{40}$ If that is indeed the case, then many physicians and hospitals are guilty of rank malpractice today. The history of these guidelines

37 See FY 2008 Final Rule, at 47209.

${ }^{38}$ FY 2009 Proposed Rule, 73 Fed. Reg. 23528, 23556 (April 30, 2008).

${ }^{39}$ FY 2009 Proposed Rule, at 23558-60.

${ }^{40}$ Pub. L. 109-171, Section 5001(c) (2005), amending Section 1886(d)(4) of the Social Security Act (42 U.S.C. section 1395ww(d)(4)). 
suggests that Medicare's conclusions are overly simplistic and ignores the many difficulties in effective implementation, including the lack of reimbursement.

Beginning in 1995, the CDC's Hospital Infection Control Practices Advisory Committee published recommendations to hinder the spread of vancomycinresistant enterococcus (VRE) (CDC, 1995). Two years later, they published interim guidelines regarding vancomycin-resistant Staphylococcus aureus (VRSA) (CDC, 2007). Both are laudable summaries of the published Medline literature, but no mention is made of reimbursement. Recommendations include private rooms for VRE infected patients; dedicated devices for VRE areas; heightened cleaning, sterilization, and isolation protocols; and extensive lab testing of screening samples (CDC, 2005). As of 2008, the CDC has 13 infection control and prevention guidelines for healthcare-associated infections, covering 1,198 recommendations (GAO, 2008). It is not clear which of these guidelines will eventually become standards for reimbursement, or what hospitals are to do when guidelines conflict or when the evidence base changes.

When MRSA is present on admission or discharge, we see germ shed externalities at play. Similarly, for CDAD, "more than one-half of the total burden of health care-associated CDAD cases have their onset in long-term care facilities" (McDonald, 2007). So long as Medicare focuses on DRG reimbursement in single institutions, germ sheds will not be directly addressed.

\section{Conclusion: Reducing MRSA Germ Shed Pollution by US Hospitals}

If the level of MRSA pollution is too high within a germ shed, then hospitals and other institutions should invest in infection control and antibiotic stewardship on a regional basis. One key question that has been identified is reimbursement who will pay? Medicare has focused on discrete providers and single episodes of care. The current and proposed rules extract financial penalties from hospitals for hospital-associated infections, even in the absence of negligence. Medicare's value-based purchasing plan is a Pigovian tax on hospital-associated infections, imposed without regard to causation or pollution in the germ shed.

When Medicare enshrines certain evidence-based guidelines as the gold standard, one concern is the federalization of the standard of care, which Congress has been historically loath to legislate. ${ }^{41}$ Federalization suppresses the market for improving medical practice, with Medicare as the final arbiter. Medicare hasn't crossed this Rubicon yet, but may do so soon with the continued implementation of value-based purchasing.

\footnotetext{
${ }^{41}$ Yet there is no question after Gonzales v. Oregon, 6 S.Ct. 904 (2006) that it has the authority to do so under the Commerce Clause.
} 
As a more modest alternative, Medicare could create DRG codes for hospital infection control and antimicrobial stewardship, and set payment rates at a sufficient level to control resistance more effectively. To address germ shed externalities, some portion of the conservation DRG reimbursement could be placed at risk based on regional achievement of antibiotic resistance goals. To facilitate this process, hospitals could be financially encouraged to undertake joint infection control and conservation initiatives within the relevant hospital markets. Activities undertaken under these programs would be exempt from fraud and abuse and antitrust laws, permitting private coordination. Top-down national guidelines could then be replaced with the practices that worked best in each local community using local surveillance data, with decisions made by the relatively small number of hospitals, long-term care facilities and other institutions in the market.

The key to effective management of MRSA pollution in a germ shed will be greatly improved and rationalized economic incentives for the various independent institutions, fostering coordination and cooperation within the germ shed. 


\section{References}

Ashby J, Guterman S, Greene T. An Analysis of Hospital Productivity and Product Change. Health Aff. 2000; 19(5): 197-205.

Binder LF. Testimony of Leah F. Binder (CEO, The Leapfrog Group), HousE OF Representatives CommitTEe on OVERsight AND Government Reform (April 16, 2008).

Centers for Disease Control and Prevention. Recommendations For Preventing the Spread of Vancomycin Resistance: Recommendations of the Hospital Infection Control Practices Advisory Committee (HICPAC), 44 MORBIDITY \& MORTALITY WEEKLY REPORT 1 (No. RR-12, Sept. 22, 1995).

Centers for Disease Control and Prevention. Interim Guidelines for Prevention and Control of Staphylococcal Infection Associated with Reduced Susceptibility to Vancomycin, 46 MORBIDITY \& MORTALITY WEEKLY REPORT 626 (1997).

Centers for Medicare \& Medicaid Services. Report to Congress: Plan to Implement a Medicare Hospital Value-Based Purchasing Program. Centers for Medicare \& Medicaid Services (US); 2007 Nov. 21.

Congressional Budget Office. Cost Estimate, S. 1932, Deficit Reduction Act of 2005 , at p. 27 (Jan. 27, 2006) (reduced spending of $\$ 300$ million total over the first five years and $\$ 800$ million total over the next five years from the entire package of hospital quality improvement legislation).

Dellit TH, Owens RC, McGowan JR, Gerding DN, Weinstein RA, Burke JP, et al. Infectious Diseases Society of America and the Society for Healthcare Epidemiology of America Guidelines for Developing an Institutional Program to Enhance Antimicrobial Stewardship. Clin. Infect. Dis. 2009 Jan 15; 44: 159-77.

Dove HG. Use of the Resource-Based Relative Value Scale for Private Insurers. Health Aff. 1994; 13(5): 193-201.

Edmond MB, Wenzel RP, Pasculle AW. Vancomycin-Resistant Staphylococcus aureus: Perspectives on Measures Needed for Control. Ann. Intern. Med. 1996 Feb 1; 124(3): 329-334.

Elhauge E. The Fragmentation of U.S. Health Care: Causes and Solutions. Oxford Univ. Press, 2010.

Frankford DM. The Complexity of Medicare's Hospital Reimbursement System: Paradoxes of Averaging. lowa L. Rev. 1993 Mar; 78: 517-668.

French GL. Clinical Impact and Relevance of Antibiotic Resistance. Advanced Drug Reviews. Adv. Drug Deliv. Rev. 2005 July 29; 57(10): 1514-27. 
Gerding DN. Metronidazole for Claustridium difficile-Associated Disease: Is It Okay for Mom? Clin. Infect. Dis. 2005 Jun 1; 40(11): 1598-600.

GaO, Health-CARe-Associated Infections in Hospitals: Leadership NeEded FROM HHS TO PRIORITIZE PREVENTION PRACTICES AND IMPROVE DATA ON THESE INFECTIONS 26-39 (March 2008). Available from: www.gao.gov/new.items/d08283.pdf.

Hearing Before the Committee on Oversight and Government Reform, House of Representatives. 110th Congress, Second Session. Serial No. 110-122. 2008 April 16. Available from: http://www.gpoaccess.gov/congress/index.html.

Henderson RR, May JJ. The Business Community Looks at DRG-Based Hospital Reimbursement. Health Aff. 1983; 2(1): 38-49 (1983).

Hyman DA. Medicare Meets Mephistopheles. Washington (DC): Cato Institute; 2006.

ICD-9-CM Coordination and Maintenance Committee, at 25 (Oct. 7-8, 2004) (proposed code 997.31).

ICD-9-CM Coordination and Maintenance Committee Meeting, Volumes 1 and 2, Diagnosis Presentations, at 9 (Sept. 27-28, 2007) (presentation of Chesley Richards, CDC).

Interim Guidelines for Prevention and Control of Staphylococcal Infection Associated with Reduced Susceptibility to Vancomycin. Morb. Mortal. Wkly. Rep. 1997 Jul. 11; 46(27): 626-628.

Klein E, Smith DL, Laxminarayan R. Hospitalizations and Deaths Caused by Methicillin-Resistant Staphylococcus aureus, United States, 1999-2005. Emerging Infect. Dis. 2007 Dec;13(12): 1840-46.

Klevens RM, Morrison MA, Nadle J, Petit S, Gershman K, Ray S, et al. Invasive Methicillin-Resistant Staphylococcus aureus Infections in the United States. JAMA. 2007 Oct 17; 298(15): 1763-71.

Kohn LT, Janet M, Corrigan JM, Donaldson MS, eds. To Err is Human: Building A Safer Health System. Washington: National Academy Press; 1999.

Laxminarayan R, Malani A. Extending the Cure. Washington (DC): Resources for the Future; 2007.

McDonald LC. Confronting Clostridium difficile in Inpatient Health Care Facilities. Clin. Infect. Dis. 2007 Nov 15; 45(10): 1266-73.

MedPAC. Letter from Medicare Payment Advisory Commission to Leslie Norwalk, Acting Administrator, Centers for Medicare \& Medicaid Services, at 18 
(June 11, 2007) available at:

http://www.medpac.gov/documents/061107 IPPS rule comment.pdf (accessed May 14, 2008). 2007a

MedPAC. Medicare Payment Advisory Commission, Public Meeting 6 (Sept. 6, 2007). 2007b

MedPAC. Report to the Congress: Promoting Greater Efficiency in Medicare, at 103-120 (June 2007) (Chapter 5: Payment Policy for Inpatient Readmissions). $2007 c$

MedPAC. Report to Congress, Variation and Innovation in Medicare, at 116 (Table 7.1) (June 2003).

Murphy D, Whiting J. Dispelling the Myths: The True Cost of HealthcareAssociated Infections. Washington (DC): Association for Professionals in Infection Control and Epidemiology; 2007 Feb.

Muto CA, Blank MK, Marsh JW, Vergis EN, O'Leary MM, Shutt KA. Control of an Outbreak of Infection With the Hypervirulent Clostridium difficile BI Strain in An University Hospital Using a Comprehensive "Bundle" Approach. Clin. Infect Dis. 2007 Nov 15; 45(10): 1266-73.

Nichols LM, O'Malley AS. Hospital Payment Systems: Will Payors Like The Future Better Than The Past? Health Aff. 2006; 25(1): 81-93.

Norrby SR, Nord CE, Finch R. Lack of Development of New Antimicrobial Drugs: A Potential Serious Threat to Public Health. Lancet Infect. Dis. 2005 Feb; 5(2): 115-19.

Outterson K, Samora JB, Keller-Cuda K. Will longer antimicrobial patents improve global public health? Lancet Infect. Dis. 2007 Aug; 7(8): 559-66.

Outterson K. The legal ecology of resistance: the role of antibiotic resistance in pharmaceutical innovation. Cardozo L. Rev. 2010. 31(3):613-678.

Pear R. Medicare Says It Won't Cover Hospital Errors. New York Times. 2007 Aug. 19; available from:

http://www.nytimes.com/2007/08/19/washington/19hospital.html.

Pearson M. Disparities in health expenditure across OECD countries: Why does the United States spend so much more than other countries? Written statement to Senate Special Committee on Aging by Mark Pearson, Head, Health Division, OECD (30 Sept. 2009). Available at www.oecd.org/dataoecd/5/34/43800977.pdf.

Pennsylvania Health Care Cost Containment Council, Hospital-Acquired Infections in Pennsylvania, Calendar Year 2006 (April 2008). 
Recommendations For Preventing the Spread of Vancomycin Resistance. Infect. Control Hosp. Epidemiol. 1995 Feb; 16(2): 105-113.

Scanlon WJ. The Future of Medicare Hospital Payment. Health Aff. 2006; 25(1): 70-80.

Talbot GH, Bradley J, Edwards JE Jr, Gilbert D, Scheld M, Bartlett JG; Bad Bugs Need Drugs: An Update on the Development Pipeline from the Antimicrobial Availability Task Force of the Infectious Diseases Society of America. Clin. Infect. Dis. 2006 Mar 1; 42(5): 657-68.

Wenzel RP. Health Care-Associated Infections: Major Issues in the Early Years of the $21^{\text {st }}$ Century. Clin. Infect. Dis. 2007 Jul 15; 45 Suppl 1: S85-8.

Wenzel RP. The Antibiotic Pipeline - Challenges, Costs, and Values. N. Engl. J. Med. 2004 Aug 5; 351: 523-26.

Werner RM, Goldman LE, Dudley RA. Comparison of Change in Quality of Care Between Safety-Net and Non-Safety-Net Hospitals. JAMA. 2008 May 14; 299(18): 2180-87.

Wright D. Testimony of Don Wright, HHS's Role in Reducing Rates of Healthcare-Associated Infections and Facilitating Quality Improvement Research, House OVersight AND Government Reform CommitTee 2-3 (April 16, 2008).

Zollner-Schwetz I, Auner HW, Paulitsch A, Buzina W, Staber PB, Ofner-Kopeinig $\underline{P}$, et al. Oral and Intestinal Candida Colonization in Patients Undergoing Hematopoietic Stem-Cell Transplantation. J. Infect. Dis. 2008 Jul 1; 198(1): $150-53$. 